Association for Information Systems AIS Electronic Library (AISeL)

ECIS 2004 Proceedings

European Conference on Information Systems

2004

\title{
An Ethnographic Study of IS Investment Appraisal
}

Debra Howcroft

University of Manchester

Robert McDonald

University of Salford

Follow this and additional works at: http://aisel.aisnet.org/ecis2004

\section{Recommended Citation}

Howcroft, Debra and McDonald, Robert, "An Ethnographic Study of IS Investment Appraisal" (2004). ECIS 2004 Proceedings. 55.

http://aisel.aisnet.org/ecis2004/55

This material is brought to you by the European Conference on Information Systems (ECIS) at AIS Electronic Library (AISeL). It has been accepted for inclusion in ECIS 2004 Proceedings by an authorized administrator of AIS Electronic Library (AISeL). For more information, please contact elibrary@aisnet.org. 


\title{
AN ETHNOGRAPHIC STUDY OF IS INVESTMENT APPRAISAL
}

Howcroft, Debra, Manchester School of Accounting and Finance, University of Manchester, Manchester UK.

McDonald, Robert, Information Systems Research Centre, University of Salford, Salford, Salford UK.

\begin{abstract}
Both academics and practitioners have invested considerably in the information systems evaluation arena, yet rewards remain elusive. The aim of this paper is to provide rich insights into the process of IS evaluation by examining some particular political and social aspects of evaluation processes. An ethnographic study of a large, international financial institution is used to compare the experience of observed practice with the rhetoric of company policy, and also to contrast these observations with the process of IS evaluation as portrayed within the literature. Our study shows that despite increasing acknowledgement within the IS evaluation literature of the limitations and flaws of the positivist approach, this shift in focus towards interpretivist understanding has had little impact on organizational practice. In addition, our observations within the research site reveal that the assumed rationality of formalised evaluation processes merely obscures issues of power and politics that are enmeshed within these processes.
\end{abstract}


A considerable amount of research has already been conducted in the information systems (IS) evaluation arena yet rewards remain elusive. This has been variously explained and in this paper we aim to contribute to the evaluation literature by our examination of some of the particular political and social aspects of evaluation processes in organizations. The intention of the research is to study at close quarters the process of IS investment appraisal and ex ante evaluation as undertaken by a large international financial institution, and to assess this within the context of the established research tradition in the area. Its objective is thus to compare the experience of observed practice in the studied organization with the rhetoric of company policy, and also to contrast these observations with the process of IS evaluation as portrayed within the literature.

The structure of this paper is as follows. We begin by providing an overview of the IS evaluation literature by highlighting the difficulties entailed. The next section discusses the ethnographic research methodology before proceeding to the analysis and findings of the study. Our intention is to highlight the point that despite increasing acknowledgement within the IS evaluation literature of the limitations and flaws of the positivist approach (typified by over-reliance on quantitative techniques and tools) this has had little impact on organizational practice. In addition, our observations of organizational practice reveal that the assumed rationality of formalised evaluation processes merely obscures issues of power and politics that are enmeshed within these processes. Finally, we conclude with a summary of the points made in the research study and a review of the argument presented.

\section{THE DIFFICULTIES OF IS EVALUATION}

In considering the evaluation question (and by implication the issue of 'value' for money of information systems), the first observation to be made is the amount of attention that the subject has demanded, both in terms of the academic literature and the level of practitioner interest (Galliers, Merali and Spearing, 1994) (Niederman, Branchaeu and Wetherbe, 1991). Yet in spite of this abundance of academic study and an increase in the organizational practice of evaluation, it appears we are nowhere nearer to finding a solution to the problems surrounding it (Ballantine, Galliers and Stray, 1999) and there is little indication that the 'hard academic, foundational questions are being widely addressed, let alone answered’ (Farbey, Land and Targget, 1998: 156).

With an increased level of investment in IS, organizations are becoming increasingly concerned to find appropriate mechanisms to measure performance and decision-makers are being pressurised to better justify their IS investments. Whilst there has always been a degree of scepticism over the 'real' benefits of IS initiatives (Earl, 1996), there is now a widespread and growing concern that IS investment does not deliver value. Yet, evaluation is seen as important to business operations, being variously described as an indispensable tool for managers, a vital organizational function, and an essential part of the management process (Hirschheim and Smithson, 1988) (Love, 1991) (Walsham, 1993). It is closely associated with decision-making (Farbey, Land and Targett, 1995) and with management desire to improve organizational economic productivity (Picciotto, 1999). So, if careful management is seen as necessary to achieve IS benefits realisation (Earl, 1996), the obvious question that arises is why so many investments appear to evolve without undergoing any formal assessment (Wilson, 1991). This absence of formal evaluation practices does not necessarily indicate a lack of endeavour within the academic or practitioner community to devise appropriate methods: "Many a scholar, consultant and practitioner has tried to devise a reliable approach to measuring the business

value of IT at the level of the firm, none has succeeded" (Keen, 1991). IS evaluation, then, appears to be characterised by a level of complexity that renders it very difficult both conceptually and practically (Hirschheim and Smithson, 1988) (Willcocks and Lester, 1999) (Zuboff, 1988). 
Reflecting the growing number of roles that information systems play within organizations, assessment of the costs and benefits depends not only on the hard technical data but also the human, social, political and cultural aspects. The technical specialists implementing the information systems are relatively well equipped to estimate the hard costs of implementation ${ }^{1}$, rather the main problem appears to be the indirect, hidden and soft costs (Hinton and Kaye, 1994) of organizational effort. The difficulties associated with this increases as information systems embrace a more prominent position within organizations and management becomes keen to demonstrate the worth of such investments.

Given this context, much attention has been paid to methodological developments in evaluation. Indeed estimates suggest that over sixty methods have been developed within the last thirty years (Renkema and Berghout, 1997). Many of these were initially based on functional and economic approaches (Hirschheim and Smithson, 1988) (Symons, 1993), but the changing role and nature of IS has rendered these techniques inappropriate given the elements of intangibility and uncertainty (Remenyi, Sherwood-Smith and White, 1996). Various taxonomies have been proposed for classification of evaluation methodologies (e.g (Irani, Ezingeard and Grieve, 1997)), with suggestions that the type of information systems might influence the choice of evaluation method. Of these different theoretical and methodological approaches to IS evaluation aside from a couple of notable exceptions (vis: (Smithson and Hirschheim, 1998) (Walsham, 1999)) the social and political issues that are inherent to this process have been consistently neglected. We concur with Smithson and Hirschheim (1998) that the concentration on the means of evaluation (better tools) has detracted attention from to its end (what to measure and why).

The attitude to evaluation within the IS literature itself mirrors the evolution of the IS field and various paradigmatic developments (Orlikowski and Baroudi, 1991). Accordingly the early reliance on functional and economic approaches, with their underlying rationalist paradigm, has more recently been discredited, with critics identifying a number of flaws (e.g. (Symons, 1993) (Willcocks and Lester, 1999)). Researchers have increasingly contrasted the limitations of evaluation approaches imposed by the positivist tradition with the potential richness achievable using evaluation practices based upon an interpretive paradigm (e.g.Walsham, 1993). The close interdependence of evaluation process and content demands a much more profound consideration of the organizational context for IS evaluation (Serafeimidis and Smithson, 2000) and a consideration of how the evaluation approach complements organizational culture (Pouloudi and Serafeimidis, 1999). However, this human and organizational focus is largely ignored by traditional methods (Serafeimidis and Smithson, 2000).

Although the tradition of IS evaluation dictates a positivist approach "where the decision maker allows the methodology to make the decision" (Remenyi, 1999), decisions are themselves based not only on so-called objective data but are influenced by cultural, political, personal and other factors (Irani, 2002) (Jones and Hughes, 2001) (Serafeimidis and Smithson, 2003). How these influences are manifested and their effect on the decision is usually the most difficult part of the evaluation process to understand. After the data has been assessed, a judgement still has to be made, and, in the absence of complete knowledge of all the alternatives and the consequences, this is an essentially political activity. Despite this observation, which reflects the nature of the intervention as necessarily a subjective process, recent research confirms previous observations (Ballantine, Galliers and Stray, 1994) that practitioners show little sign of moving away from quantitative, financially-based data as a basis for IS investment appraisal (Ballantine and Stray, 1998) (Lycett and Giaglis, 2000). Financial reviews of costs and benefits still represent the most common aspect of evaluation procedures and financial techniques such as NPV (Net Present Value) and IRR (Internal Rate of Return) predominate (Farbey, Land and Targett, 1995). Despite the growth in the legitimacy of the interpretive paradigm in IS evaluation, little has changed in the hearts and minds of the decision-makers, who continue to rely on hard, financial calculations (Farbey, Land and Targett, 1995).

\footnotetext{
${ }^{1}$ although even this is contentious
} 
The tendency to pursue IS evaluation as an overly rationalistic approach is understandable given that historically, the process of IS development is characterised by rationality whereby actions are justified on rational grounds and the appropriate organizational rituals are adhered to (Boland and Pondy, 1983). Such a perspective is epitomised by the assumption that information systems are designed to contribute to specific ends, ends that can be articulated, are shared, and are objective. Once built and installed, the system, itself an 'icon of rationality' (Franz and Robey, 1984), will improve the efficiency or effectiveness of decision-making processes and thus represent a sound investment. The tools and methodologies associated with the IS evaluation process also possess an aura of rationality, often based on mathematical and logical processing techniques as opposed to reliance on human intuition, judgement and politics. This rational myth assumes a 'foreground' position, enabling organizational actors to behave in accordance with certain cultural expectations. Yet despite the predominance of the rational myth, the 'background myth' of political behaviour is of equal importance (Boland and Pondy, 1983). In fact, for some twenty years the political elements of IS development within organizations has been commented on. Take, for example, the following:

“....political interests are of basic importance to the actors in the organization. Political actions are not isolated episodes to be interpreted within the context of rational problemsolving efforts. It is the other way round. The rational elements are tools used by participants to gain new ground or to protect ground already won. They also serve as 'facades' to mask political motives and legitimise self-interest."

(Franz and Robey, 1984: 1209)

The focus on the rational aspects of evaluation fails to recognise the possibility that the outcome of such processes can be decided ahead and devised to support other managerial decision-making - a phenomena known as 'de facto decision-making' (Vroom and Yetton, 1973). Therefore, in this paper, whilst we are not attending explicitly to what to measure, rather we attend to the issue of why evaluate. One conclusion in this respect is that evaluation is a highly politicised process that is employed to justify investment and decisions already made - no matter what rhetorical disclaimers such as objectivity, rationality or quantitative measurement are proffered. The implication for IS researchers and practitioners, is that when employed to carry out evaluations we are engaged in a political game that is skewed from the outset, often in favour of the sponsors. In this paper we aim to shed some light on this 'thorny problem' by considering both the rational and the political motivations surrounding the issue of IS evaluation. Specifically, we focus on the dissonance between espoused rationality and the lived experience of technology, which is more typically characterised by power, politics, and conflict. Whilst IS evaluation seems central to any discussion of systems development, there is often a substantial gap between espoused theory and concrete practices and the ethnographic study, which follows next, highlights some of these contradictions.

\section{RESEARCH METHODOLOGY}

The purpose of this research project is to explore the political and social aspects of evaluation processes by highlighting the subjective element of these procedures despite the tendency to focus on the rational. Given the nature of the subject under consideration and the need to understand the evaluation processes in situ, ethnography offers an appropriate research approach. Ethnographic research provide valuable techniques for studying the social, political and organizational contexts of IS phenomena (Myers, 1999) whilst also attempting to 'bridge the gap' between the different concerns of academics and practitioners (Harvey and Myers, 1995). Given that one of our objectives is to consider how the shift in focus in the IS evaluation literature has impacted upon the conduct of evaluations within institutional contexts, ethnography enables the generation of knowledge that is appropriate to both academics and practitioners (Harvey and Myers, 1995).

One of the most valuable aspects of this research technique is its depth since the ethnographer 'lives' the situation under research, and experiences this for a considerable period of time. This provides insights into what people are doing and not simply what they are saying (as reported, say in interview 
data). Given the longevity of an ethnographic study, the researcher can build up a richer understanding of the actors, the attitudes, culture and artefacts of an organization, and the broader context within which they have significance. However, despite the obvious strengths of ethnographic approach, it is not without its practical difficulties, which are often perceived in terms of time demands and access to in-depth field observation (Fetterman, 1998) (Yin, 1989). This issue was addressed as one of the authors was based within (not happy with 'employed by' - need a different phrase) the organization at the start of the study, thus allowing him to 'go native' whilst providing access to the research data over a significant time period. The author held a pivotal position with the IS evaluation process, enabling him to observe and participate in all stages of the process.

The role of the author as both researcher and active participant can be problematic in itself. In particular the researcher was concerned with how he might influence the practicalities of the process. Accordingly, this presented a unique contextual example of the reflexive concern that is significant to any ethnographic study. The responsibility of the ethnographer, however, did not extend beyond facilitating the workings of the IS evaluation process. Although he empathised with the various social groupings, he was not an active stakeholder with a vested interest in the outcome of any particular investment proposal and as such was an impartial 'guardian of the process'. This responsibility was interpreted not in terms of compliance with the official process, but as facilitator of the activity required to reach an investment appraisal decision.

The research itself lasted for a period of six months and was carried out largely in synchrony with the appraisal and evaluation cycles, which took place on a monthly basis. Initially a period of organizational 'induction' was undertaken, which assisted the ethnographer's understanding of the organizational history and the context of the IS evaluation process. The induction included interviewing a wide variety of stakeholders at differing levels of seniority within the organization. This was useful for establishing some initial background context and was also an appropriate 'way in' to the research. The initial interviews were carried out with representatives from the following organizational sub-units:

- The IT group (from each distinct technology area or discipline, amounting to twelve interviews)

- The different major business areas (at senior and middle management level, amounting to six business units and fourteen interviews)

- The Finance division at senior, middle and junior management level (a single interview/meeting).

Generally, the interviews were undertaken on a one-to-one basis and followed a semi-structured approach, although for operational reasons the finance interview was undertaken as a single meeting between the researcher and three finance representatives at different organizational levels. The initial interviews led to a review of further background documents and materials. Although the observational data and other data artefacts were collected, as far as was possible on a daily basis, review of this data and any active development of themes or pattern identification was not undertaken until the end of each cycle, though often impressions and hunches were formed and collected during the IS investment appraisal cycle.

In addition to the observational material, a continuous review of other material was conducted including emails, documents, forms, databases and spreadsheets, organization charts, flowcharts as well as web-based material. A variety of analytical techniques were used to assess this, including content analysis, in order to develop themes to feed into the ongoing research. Simultaneous literature review and the identification of specific themes was allowed to influence the ethnography in so far as was practical by providing continuous input to the process in support of the reflexive and selfanalytical nature of the ethnography itself. In this way, multi-level assessment, check pointing, reviewing and development of the research approach provided an emergent research strategy. This iterative approach of data collection, analysis and refinement of approach or confirmation of emerging themes, characterised the ethnography throughout its lifetime. In this way the research can be said to have evolved as it proceeded. The process may figuratively be characterised as bottom-up, top down and inside-out in nature. The data collection was supported 'interactively' that is concurrently by analysis and creative interpretation, which fed into and influenced the subsequent approach. 
As noted elsewhere (Harvey and Myers 1995; Myers 1999), the write-up of ethnographic studies does not easily lend itself to conference and journal length output. Consequently, the section that follows is of necessity, segmented, and can only offer a microcosm of the larger picture.

\section{4}

FINDINGS AND ANALYSIS

As stated above, this ethnographic study is a slice from the organizational life of a large, European, bureaucratic company. The study is not intended to draw conclusions or even make recommendations, but simply open up channels for further discussion on the nature of IS evaluation. The organization of concern was selected for this study because it provides a typical example of institutionalised IS evaluation processes. The reader will also note the existence of a number of contradictions between what is claimed on behalf of company policy regarding the 'official' evaluation process and observed practice.

\subsection{Background and setting}

The organization under review is a UK-based subsidiary of an International Bank with its headquarters outside the UK. The history of the organization (as it presented itself) is that of a successful financial services company with a significant and growing market share. The tale that follows includes a number of different stakeholder groups, often with differing interests. Details are provided of these groups who featured as dramatis personae in the story (table 1).

\begin{tabular}{|c|c|}
\hline IT group & $\begin{array}{l}\text { - the technologists based in the UK organization responsible for } \\
\text { application development, infrastructure development and } \\
\text { operational support }\end{array}$ \\
\hline $\begin{array}{l}\text { IT Assessment Group } \\
\text { (ITAG) }\end{array}$ & $\begin{array}{l}\text { - a subset of the IT group that is responsible for assessing proposed } \\
\text { developments and creating initial estimates for costs, complexity } \\
\text { and development timescales. }\end{array}$ \\
\hline $\begin{array}{l}\text { Business \& IT Consulting } \\
\text { Services (BICS) }\end{array}$ & $\begin{array}{l}\text { - a team of business consultants responsible for the initiation of } \\
\text { business system developments. Initiation includes working with the } \\
\text { business areas in identifying business opportunity or requirement, } \\
\text { proposing a development to the ITAG, using the defined evaluation } \\
\text { process to the point of decision whether to make the investment, } \\
\text { and providing business prioritisation input for the project } \\
\text { management team for approved systems development investments. } \\
\text { the operational business units within the UK business. }\end{array}$ \\
\hline Finance & $\begin{array}{l}\text { - core financial organization within UK with traditional financial } \\
\text { responsibilities. In the IS evaluation process, responsible for } \\
\text { validating the financial cost/benefit analysis for proposed } \\
\text { information systems investments, for confirming funding for } \\
\text { investments and for tracking the realisation of financial benefits of } \\
\text { information systems investments post implementation. }\end{array}$ \\
\hline Chief of Operations & $\begin{array}{l}\text { - senior executive responsible for reviewing all proposed information } \\
\text { systems investments before submission to corporate headquarters } \\
\text { for review. }\end{array}$ \\
\hline $\begin{array}{l}\text { Corporate Resources } \\
\text { Department (CRD) }\end{array}$ & $\begin{array}{l}\text { - responsible for assessing, challenging and validating all proposed } \\
\text { information systems investments prior to review by senior } \\
\text { executive committees and for approval of low-value investment } \\
\text { requests }\end{array}$ \\
\hline
\end{tabular}

Table 1: $\quad$ IS Evaluation Stakeholders

As is typical of large bureaucratic organizations, the evaluation process consisted of approximately twelve stages (with sub-divisions) and involved eight or more organizational functions. Each of these 
stages was observed in detail, but for simplicity the key aspects that illustrate the dissonance between organizational rhetoric and organizational practice will be reported here. Historically, the organization has been involved in the routine conduct of IS evaluations, but the evaluation process reported here is one that has been recently introduced within the organization.

\subsection{Initial stages: Scan Business Environment}

In order to generate potential ideas for IS development it was the responsibility of the various business areas to scan the business environment and identify any new opportunities. Business \& IT Consulting Services (BICS) liased between the business areas and the IT department in order to ensure sufficient cooperation had taken place and that the two groups were in agreement that the investment proposals were both technically feasible and practical from a business perspective. However, one of the drawbacks was that BICS offered incomplete and patchy representation of business areas as a number of business units' resisted participation in this process. Consequently, BICS did not have a full picture of the UK business environment and so the process of business facilitation was referred to (by a BICS consultant) as "the blind leading the blind".

\section{Investment Request Submission}

The next stage is the Technology Project Investment Request, which involved the completion of highlevel business requirements as well as business costs and financial benefits. This request included an option for 'fast-track' IS developments which included, for example, initiatives to meet contractual commitments or legal requirements, which could be expedited for approval.

It soon became clear that the Technology Project Investment Request was treated mainly as a way to get a potential investment into the process and was regarded of little value apart from being a vehicle for collecting the required signatories' signatures. It was later seen to have little relevance as BICS management was informed by the CRD that the key decision-makers did not refer specifically to the details but rather summarised the request into a presentation format that relied upon verbal explanation of the project in order to elicit an executive decision. Given this disclosure, BICS relaxed their requirement of accurate and high-quality information.

Surprisingly, there was no difference in approach when assessing proposals. Thus low value investments queued patiently alongside the more substantial investments. Furthermore, despite the ability to provide support for 'fast-track' projects, during the study every 'fast-track' justification (23 in number) was ignored and proceeded in a manner that was identical to 'normal' investment proposals.

\subsection{Business System Services Review}

The BICS review was a weekly forum at which all new proposed submissions were presented and discussed. One of the stated objectives was to leverage a cross-divisional position, to add value in technology decisions and implementations. Accordingly each request was reviewed with the intention of identifying any synergies and potential efficiencies by expanding the scope of or altering the request in some way. Yet, in practice there were only four occasions where a material change was made to the request arising from this meeting. The practicalities of holding a meeting consisting of all the relevant stakeholders, in itself proved to be a significant challenge which was exacerbated by the fact that BICS failed to represent certain powerful departments that elected not to participate. As the evaluation cycles progressed, it became clear to BICS that the process was rigorous, demanding and intensive. The number of initial submissions that proceeded to final approval was approximately 1 in 5. One BICS representatives made the observation that this meeting, even if fully attended, would be "wasting its time, $80 \%$ of the time". 
A group made up of representatives from the IT department then assessed each request based on an estimate comprising: costs to deliver, timescales and levels of complexity. The IT assessment group (ITAG) were expected to provide such estimates within the context of a single meeting and they struggled to do so. Many expressed their concern regarding their ability to provide cost estimates based on such limited conceptual requirements. Allied to this discomfort was the demand for an immediate estimate, and on numerous occasions the ITAG preferred to defer an estimate until the next meeting. This delaying tactic can also be seen as an indication of their resistance to working practices that they felt had been imposed upon them. This dislike of the process allowed delayed estimates to become established practice, so that the ITAG stated that it was their objective to provide estimates at the meeting 'only where appropriate'. The number of IS development requests that received estimates at these meetings was less than $50 \%$.

At this stage in the process the information required by corporate headquarters from ITAG included: Project name, business sponsor, BICS relationship manager, complexity assessment, financial assessment (the cost estimate), interim funding requirements, timing, and whether or not the project was an fast-track request. However, it became clear during discussions with BICS that subsequent reviews that considered the investment proposals referred only to the financial assessment and all the other information was disregarded. Over time, the practice of accurately trying to supply the required information became completely undermined.

Because of the lengthy approval process, ITAG and BICS expressed their frustration that every type of development request was treated in the same manner. Whilst there was an acceptance that significant projects should be closely scrutinised, there was a feeling that smaller projects were stifled because of a lack of willingness to invest in the process required for approval. As a result, a number of tactics were employed to facilitate development without having to go through the full rigours of the evaluation process. Thus, many potential projects were submitted as 'work requests' via IT helpdesk trouble tickets, thus bypassing the formal evaluation process. As IT developers and BICS representatives agreed on their local priorities some developments were undertaken without ever entering the formal process. In addition, a number of 'deals' were made at ITAG, whereby IT staff proposed to categorise costs in a particular way such that the bill for a development would be minuted as zero. Technically even these zero-costed 'projects' should have been steered through the process but they also bypassed the formal evaluation.

\subsection{Creating a 'business case'}

The output of the ITAG review was sent to BICS so that they could construct a 'business case' to be presented to the finance department for validation. The 'business case' was used almost exclusively to describe what was essentially a cost/benefit analysis (CBA) detailing only hard costs and benefits and consisted of little more than an Excel spreadsheet. Large investments required completion of a corporate CBA spreadsheet with five-year projections and calculations of the usual capital investment financial measures (such as, NPV, IRR, and PP (Payback Period)).

The finance department, who were later required to ratify these 'business cases', introduced templates outlining 'allowable' financial models to be used by BICS which were predominantly based on financial details over any other considerations. The only benefits categories that could be shown on the investment appraisal request form were: increase in corporate revenues; reduction or avoidance of corporate costs; and, reduction in corporate losses due to bad debt / fraud. Projects with large benefits in the increase in corporate revenues category received the most prompt attention as compared with other proposals. Many of these projects had the endorsement of senior management. This was even to the extent that on more than one occasion significant projects were started by the IT department before the project had even entered the formal evaluation process because it was assumed that senior executives would subsequently approve of this sort of development and so 'nod through' the project. 
Every project received some financial assessment, which often amounted to reviewing costs so that these might be tracked and reviewed as the project progressed. However, for many projects, even those that were required in order to comply with legal requirements or directives, there was a pragmatic assessment made on the basis of risk exposure and the cost of potential penalties as against the cost of the investment and the timing of the spend.

One interesting development that emerged during the study was the growing awareness by the relevant stakeholders of the overwhelming importance of the financial case, expressed in hard numbers. Initial investment proposals, which included business benefit details, were soon amended as business benefits were simply no longer detailed. The reasons stated were two-fold. Firstly, the effort to produce a benefits statement was too much of an overhead given the possibility that prohibitive costs may be supplied by ITAG. As one BICS representative commented: "we're not going to spend time working out the benefits before we know it's worth it". Secondly, it was admitted that once the costs were known, a benefits assessment that would prove attractive could be 'manufactured' to provide the best chance of approval. BICS managers working within the business areas colluded in this process. As it became clear which kinds of investments were being approved, this intelligence was shared, as one business manager commented: "If it’s got a payback longer than two years, forget it!"

\subsection{Finance \& Funding Review}

Verification from the finance department was needed before a project could be further progressed. Costs identification and assessment was based purely on hard technology and business costs with no attempt to capture softer costs of implementation. Although these benefits might be used as supporting verbal evidence, this was only ever referred to in support of financial benefits identified and modelled using financial tools. For each investment -irrespective of value - NPV (5 year), PP and IRR were necessary. The financial review was regarded by BICS as a 'black and white' process, and as long as the calculations had been completed in a manner that finance would find acceptable there was little room for discussion. In this sense the evaluation was little more than a case of presentation.

Despite the so-called rigour of the evaluation process, several projects, which had been previously rejected at some stage, later re-emerged with the 'unacceptable' details changed or removed. Thus, one project, which had a supporting business case that was deemed to be financially unattractive and was rejected, simply repackaged the business case with differently stated benefits. For powerful business managers who wanted the project to be implemented they would sidestep the process by making the presentation of the benefits more appealing. The finance department was put under pressure to validate the new case and instructed to defend the new figures vigorously. When questioned about this practice, a finance representative conceded that the business cases were often artificial and the decision as what to do had already been made and could not be influenced. The power of the finance group was such that it was seen in purely administrative terms, with one senior finance manager confiding: "I’m the highest paid administrative assistant in this company".

\subsection{Chief of Operations Review}

The final UK review was an assessment by the Chief of Operations to ratify the investment proposals before submission to corporate headquarters for further review. Although the final UK-based review was expected to be a rubber-stamping exercise, in practice more active participation was demanded by the Chief of Operations. Since stakeholders at corporate HQ dominated the executive decision-making process, there was sensitivity about the scrutiny that would be applied to requests, especially those that were politically sensitive. For this reason there were occasions where a project would be stopped at this stage as the visibility of the project was deemed to be unnecessary. This would result in the investment being 'approved' outside of the official process and work commencing without corporate ratification. Here, the researcher observed a number of occasions when the Chief of Operations decided that a particular project did not need to proceed through the approval process, he approved immediate commencement of the project and the investment proposal was then withdrawn. 
Once investment proposals had been reviewed within the UK they were submitted to the corporate resources department (CRD) for further review. Before CRD would even consider the merits of the IS proposal, proof of adherence to the evaluation process was needed in the shape of signatures and form completion. As the study progressed the amount of validation material required increased or changed to such an extent that the process was inconsistent from one cycle to the next. It appeared that there was a deliberate policy to challenge the resolve of the sponsoring divisions. The policy of putting practical hurdles in front of investment proposals was openly compared (by a key actor from the CRD) to the theory of evolution, with only the fittest of the investment proposals surviving. The CRD team admitted that their intention was to test the willingness of BICS to jump over the hurdles that they invented along the way, as one CRD member noted: "if a business area doesn't come banging on my door, I'm guessing they're not really serious about it. If they really believe in the numbers, they'll make it happen". This was seen as a way of 'separating the wheat from the chaff'. The exchanges between CRD and BICS were often light-hearted in nature and seen on both sides as something of an intellectual game. One member of CRD admitted that their hold over the IS development process was "theoretical rather than practical". Typical of this was an email auto signature on CRD emails:

My usual disclaimer: What could be perceived as petty bureaucracy is intended to ensure we make business decisions based on the best information available from the proper authorities.

The light-hearted nature of much of these communications between BICS and CRD allowed both organizations to discuss openly their feelings towards the process. The 'pointlessness' and 'futility' of the reality of the job was acknowledged by one member of the CRD department,

We all know that statistics are crap and can be used to support any bias we choose to promote ....

On one occasion a very small investment proposal was discussed over a period of four months before CRD was satisfied to approve the proposal. Both BICS and CRD agreed that the cost of putting the investment through the approval was probably twenty times greater than the value of the investment, yet this overhead was never factored into the costs of an investment.

CRD and Senior Executive Review

For low value investment proposals CRD could provide approval. For higher value investments CRD was required to present the investment proposal at the executive committees. Given the scrutiny by the CRD function, it was unlikely that anything that was taken to the executive committees would be rejected. This was something of a point of honour for CRD and on the occasion that investment proposals were not approved, this was taken as a personal slight. In fact during the six-month study the committee declined only two items outright. One significant investment was deferred and the reason for this was that a member had attended the committee for the first time and appeared to have "got out of bed with a sore head" and had been trying to "make a noise". BICS were assured that there would be no problem next time and were not required to answer any further supplementary questions about the proposal. When the proposal was approved at the subsequent committee meeting, CRD commented that the proposal had gone through unopposed with very little comment. "I just jiggled the presentation up a bit - sometimes it just depends on their mood.”

\subsection{Observations outside of the Process}

Throughout the study it became clear that in practice there were many examples of investment proposals, which managed to avoid going through the prescribed evaluation process.

- High-value Corporate investments 
High value investments often did not go through any formal evaluation process as decisions were taken directly by executive management within corporate headquarters. This entailed considerable risk since these decisions were less likely to have been based on a full understanding of costs. Indeed, in one example IS/IT costs (which were substantial) were underestimated by a factor of approximately four. The reasons given for this avoidance of official procedure were based on the need for a quick response, although the factor of error was the subject of enormous political sensitivity. This investment 'proposal' was later put through the official evaluation process as a purely academic exercise in order to act as post mortem review by executive management. On this occasion CRD was required to dissect the business case in extreme detail.

- Very small investments

Because of the time required to pass through the bureaucratic process, there was sometimes collusion between business areas, BICS and ITAG to find ways of initiating the development work outside of the process, for example by exploiting other existing work structures or practices.

- Contractual commitments.

Often, the Marketing department would enter into contractual agreements with third parties, which required some type of IS development effort in order to fulfil contractual obligations. As many of these obligations were usually under tight time constraints, the IT department were pressurised into carrying out the development without prior approval. On each occasion, BICS attempted to take the IS development request through the approval process even though work had already commenced. This represented a considerable gamble by BICS and on two occasions this risk was exposed when CRD were unconvinced of the validity of the financial case and considered rejecting the investment request. BICS were then forced to admit that the work had already begun and that any decision to proceed was illusory.

- Projects with informal backing from senior executives.

Whenever senior executives were convinced that an IS development was worthwhile, work was often initiated outside of the process. Here again there was no formal authority to proceed except for socalled executive intuition. Again, these proposals were formally escorted through the evaluation process to legitimise the decision, which had already taken place outside of the process. As a point of interest, these were the same executives who made the decisions at the senior executive committees to which investment proposals were submitted.

\section{SUMMARY AND CONCLUSION}

Our overview of the landscape of the IS evaluation literature reveals a trend that is mirrored in the IS field more generally; that is, the move towards the increasing concern with the social and organizational aspects of IS and, correspondingly, an increase in the use of interpretivist research as a lens to make sense of these processes. We ask the question, how is this trend reflected in organizational practices of IS evaluation? Are attempts being made to understand the 'softer' elements of evaluation that consider the human and organizational aspects of IS development and use? Is there an increasing recognition of the political process of evaluation and a move away from hard, quantitative measures? In order to address these issues an ethnographic study of a large financial organization with institutionalised evaluation processes was conducted. Ethnography was felt to be particularly appropriate since it enabled the researcher to move beyond what people were saying and observe what people were actually doing. One problem researchers are often faced with in interview situations is the 'hawthorne effect' whereby participants respond in ways in which they think you want them to respond. By contrast, intensive ethnographic study enables the researcher to become deeply immersed in the organization to study the social and cultural context of the phenomena of interest and thus move beyond surface explanations. Had the study consisted of face-to-face interviews, arguably it would have been more difficult to reveal hidden agendas, power centres, contradictions, and behaviour that went against the 'orthodoxy'. Interviewees would be inclined to provide a 'sanitised' version of organizational life, which merely replicated 'formal' accounts of organizational processes and procedures. The ability for the interview situation to reflect anything other than the norms for 
behaviour in interview situations has been seriously questioned (Silverman, 1985) (Silverman, 2000). Instead, ethnographic observation at close quarters over a considerable period of time enabled other elements to come to light, aspects, which would have been difficult to access with, say, quantitative techniques generally or a qualitative interview-based approach.

Whilst some may see the study as extreme, the results of this research reveals that there is a political context to all development and implementation activities that affects, if not frames, the evaluation process. The implications for those of us involved in evaluations are recognition of the social, economic, and political conditions that constitute the context within which evaluations take place. For example, the study reveals instances were some actors deliberately undermined the IS evaluation process (as a form of resistance); others sought legitimate alternative means ('loopholes' or workarounds) to achieve their own ends or simply in order to avoid the lengthy, drawn-out process before securing project approval; and others (usually senior executives) deliberately bypassed the process so that they could push through their own sponsored projects. Yet, these various stakeholders were not unaware of the political manoeuvrings that took place and often there was acknowledgement of the futility of the process and its role in the 'rubber-stamping' of projects that may have already been started. They simply 'played the game' by following official procedures on most occasions, whilst cleverly avoiding them when it suited them.

The research study illustrates the predominance of the formal-rational management paradigm with heavy reliance on quantitative analysis to support decision-making. However, this quantitative data provided input to decision-making in complex ways. The organization's ostensible rationality would suggest that the quantitative evaluation data provided input to a decision-making process mechanism which itself generated a decision on behalf of the organization. However, observations suggest that the data were often treated in a less positivist manner and those outcomes from the decision-making process owed much to the political positioning and manoeuvring of the various stakeholders, with the 'official' rationality of the evaluation process being used to justify decisions taken in a far less rational or scientific manner. These findings are consistent with Ballantine's observation (1994) that there is a reluctance to move away from the comfort of traditional 'hard' evaluation techniques towards the more interpretive paradigm suggested increasingly in the literature. Within a large, bureaucratic financial organization, this is perhaps unsurprising. However, this positivist machinery in fact masks the less comfortable reality that significant business decisions are being taken outside of the organization's positivist management orthodoxy. Furthermore it seems that the formal-rational process of approval also influences the type of information system proposed, such that efficiencybased applications predominate. While these may be worthy in themselves, there is a risk of diminishing returns when pursuing this type of limited application portfolio and the process of innovation may be constrained or even stagnate. This is itself reflected in the rather limited strategic intention within the organization, which emphasises growth of market share by acquisition over more imaginative forays into new product sets or diversifications. In this respect, the shackles of the IS evaluation process risk stifling innovative development.

\section{References}

Ballantine, J., Galliers, R. and Stray, S. (1994). Information system/technology investment decisions the use of capital investment appraisal techniques in organisations. Proceedings of the 1st European Conference on IT Investment Evaluation, Henley, Uk, 148-166.

Ballantine, J., Galliers, R. D. and Stray, S. J. (1999). Information Systems/Technology evaluation practices: evidence from UK organizations. Beyond the IT Productivity Paradox. S. Lester (ed.). John Wiley and Sons, Chichester: 123-150.

Ballantine, J. and Stray, S. (1998) Financial appraisal and the IS/IT investment decision making process, Journal of Information Technology 13(1): 3-14.

Boland, R. J. and Pondy, L. R. (1983) Accounting in organizations: a union of natural and rational perspectives, Accounting, Organanizations and Society 8: 223-234. 
Earl, M. (1996) Putting Information Technology in its Place: A Polemic for the Nineties, Journal of Information Technology 7: 100-108.

Farbey, B., Land, F. and Targget, D. (1998) Editorial, European Journal of Information Systems 7: $155-157$.

Farbey, B., Land, F. F. and Targett, T. (1995) A Taxonomy Of Information Systems Applications: The Benefits' Evaluation Ladder., European Journal of Information Systems 4: 41 -50.

Fetterman, D. (1998) Ethnography. Sage Publications,Thousand Oaks, CA.

Franz, C. R. and Robey, D. (1984) An investigation of user-led systems design: rational and political perspectives, Communications of the ACM 27(12): 1202-1209.

Galliers, R. D., Merali, Y. and Spearing, L. (1994) Coping with Information technology? How british executives perceive the key information systems management issues in the mid-1990s, Journal of Information Technology 9(4): 223-38.

Harvey, L. and Myers, M. (1995) Scholarship and Practice: The Contribution of Ethnographic Research Methods to Bridging the Gap, Information Technology \& People 8(3): 13-27.

Hinton, C. and Kaye, G. (1994) The hidden investments in information technology: The role of organisational context and system dependency, International Journal of Information Management 16(6): 413-427.

Hirschheim, R. and Smithson, S. (1988). A critical analysis of IS evaluation. Information Systems Assessment: Issues and Challenges. G. B. Davis (ed.). North-Holland, Amsterdam: 17-37.

Irani, Z. (2002) Information systems evaluation: navigating through the problem domain, Information \& Management 40: 11-24.

Irani, Z., Ezingeard, J. and Grieve, R. (1997) Integrating The Costs of a Manufacturing IT/IS Infrastructure into the Investment Decision-Making Process, Technovation 17(11/12): 695-706.

Jones, S. and Hughes, J. (2001) Understanding IS evaluation as a complex social process: a case study of a UK local authority, European Journal of Information Systems 10: 189-203.

Keen, P. (1991) Shaping the future: business design through information technology. Harvard Business School Press,Boston, Mass.

Love, A. (1991) Internal Evaluation: Building Organizations From Withi. Sage Publications,Newbury Park, CA.

Lycett, M. and Giaglis, G. (2000). Component-Based Information Systems: Towards a Framework for Evaluation. Proceedings of the 33rd Hawaii International Conference on Systems Sciences, 1-10.

Myers, M. D. (1999) Investigating Information Systems with Ethnographic Research, Communication of the AIS 2: 1-20.

Niederman, F., Branchaeu, J. C. and Wetherbe, J. C. (1991) Information systems management issues for the 1990s, MIS Quarterly 15(4): 475-99.

Orlikowski, W. J. and Baroudi, J. J. (1991) Studying IT in organizations: research approaches and assumptions, Information Systems Research 2(1): 1-28.

Picciotto, S. (1999). Introduction: What Rules for the World Economy? Regulating International Business: Beyond Liberalization. R. Mayne (ed.). Macmillan, London.

Pouloudi, A. and Serafeimidis, V. (1999). Stakeholders of Information Systems Evaluation: Experience form a Case Study. Proceedings of The Sixth European Conference on IT Investment Evaluation, Brunel University, Uxbridge, 91-98.

Remenyi, D. (1999) Stop IT Project Failures Through Risk Management. Butterworth Heinemann,Oxford.

Remenyi, D., Sherwood-Smith, M. and White, T. (1996). Outcomes and benefit modelling for information systems investment. Proceedings of the 3rd European Conference on Information Technology Investment Evaluation, 101-119.

Renkema, T. and Berghout, E. (1997) Methodologies for Information Systems Investment Evaluation at the Proposal Stage: A Comparative Review, Information and Software Technology 39: 1-13.

Serafeimidis, V. and Smithson, S. (2000) Information systems evaluation in practice: a case study of organizational change, Journal of Information Technology 15: 93-105.

Serafeimidis, V. and Smithson, S. (2003) Information systems evaluation as an organizational institution - experience from a case study, Information Systems Journal 13(251-274). 
Silverman, D. (1985) Qualitative Methodology and Sociology. Gower,Aldershot.

Silverman, D. (2000) Doing Qualitative Research: A Practical Handbook. Sage,London.

Smithson, S. and Hirschheim, R. (1998) Analysing Information Systems Evaluation: Another Look at an Old Problem, European Journal of Information Systems 7: 158-174.

Symons, V. (1993) Evaluation and the failure of control: information systems development in the processing company, Accounting, Management and Information Technology 3(1): 51-76.

Vroom, V. H. and Yetton, P. W. (1973) Leadership and Decision-making. University of Pittsburgh Press,Pittsburgh.

Walsham, G. (1993) Interpreting Information Systems in Organizations. John Wiley \& Sons, Chichester.

Walsham, G. (1999). Interpretive evaluation design for information systems. Beyond the IT Productivity Paradox. S. Lester (ed.). John Wiley and Sons, Chichester: 363-380.

Willcocks, L. and Lester, S. (1999). In search of information technology productivity: assessment issues. Beyond the IT Productivity Paradox. S. Lester (ed.). John Wiley and Sons, Chichester: 6998.

Wilson, T. (1991) Overcoming the Barriers to the Implementation of Information System Strategies, Journal of Information Technology 6: 39-44.

Yin, R. K. (1989) Case Study Research: Design and Methods. Sage,London.

Zuboff, S. (1988) In the Age of the Smart Machine: The Future of Work and Power. Basic Books,New York. 